\title{
Violence and Abuse: What Child Psychiatrists Need to Know
}

\author{
David L. Corwin \\ Guest Editor, Board Chair, Academy of Violence and Abuse
}

In this issue, are the first three of five reviews addressing various aspects of childhood trauma and maltreatment invited as part of a collaboration between the Korean Academy of Child and Adolescent Psychiatry (KACAP) and the Academy on Violence and Abuse (AVA). The AVA is a global interprofessional society dedicated to promoting increased awareness and skill among health professionals about the relationship between violence and abuse and adverse health impacts across the life-course.

The first of these reviews is by Susie Wiet, MD, a child, adolescent, adult psychiatrist, who is also boarded in addiction medicine. She addresses the role of childhood trauma in the development of addiction. Dr. Wiet serves on the AVA Board of Directors and has led an effort in Utah, the Trauma-Resiliency Collaborative, to raise community awareness about trauma, resiliency and their relationship to health. She briefly summarizes the current understanding of how childhood adversity can be toxic stress that alters the brain's biology leading to increased susceptibility to addiction. ${ }^{1)}$ Understanding the ways that severe stress impacts the developing brain helps clinicians understand the increased risk for a variety of psychiatric symptoms, disorders, including addiction, and other longterm health problems facing those who experience childhood adversity and toxic stress.

Brooks Keeshin, MD and Jeffrey Strawn, MD review current knowledge about the most effective treatments for PTSD in children and adolescents, including the research addressing the use of psychotropic medication. ${ }^{2)}$ Dr. Keeshin is also an AVA board member. He is quadruple boarded in psychiatry, child and adolescent psychiatry, pediatrics, and child abuse pediatrics and is currently working to improve screening and treatment of PTSD in children and adolescents. Dr. Strawn is a child, adolescent, and adult psychiatrist doing neuroimaging and clinical trials research along with clinical patient care. Keeshin and Strawn have collaborated on research and publication addressing this topic for several years. The knowl-

This is an Open Access article distributed under the terms of the Creative Common Attribution Non-Commercial License (http://creativecommons.org/licenses/by-nc/3.0) which permits unrestricted non-commercial use, distribution, and reproduction in any medium, provided the original work is properly cited. edge summarized in their review is essential to child psychiatrists wishing to provide evidence-informed care for the traumatized youth they evaluate and treat.

Joan Durrant, $\mathrm{PhD}$ and Ron Ensom have led efforts in Canada to end the corporal punishment of children. In their review of the last 25 years of research on corporal punishment, they acknowledge the Republic of Korea's 1991 ratification of the United Nation's Convention on the Rights of the Child (CRC) and subsequent legislation to end corporal punishment. ${ }^{3)}$ Indeed, the Republic of Korea made this policy shift early among the world's nations. Since the completion of their manuscript, two more countries, Paraguay and Slovenia, have banned corporal punishment of children in all settings. All countries on earth have signed now the CRC except for the USA. The science connecting corporal punishment with increased aggression and a number of other negative outcomes for children, including several psychiatric symptoms and disorders is compelling. There is no evidence for any positive benefit. Seoul was wise to ban Corporal punishment in all settings five years ago. Korean child psychiatrists can help spread that ban to the rest of Korea and support the ending of corporal punishment by educating parents and referring them to parent training resources that teach alternatives to corporal punishment. This may be one of the most important preventive actions that child psychiatrists and other health professionals can do to improve the lives, health and mental health of children.

Two more reviews complete this first collaboration between AVA and JKACAP. These reviews will be published later in 2017. One addresses the impact of witnessing intimate partner violence upon children and adolescents and its relationship to other childhood adversities and adult outcomes. The others compare the rates of child maltreatment from a number of Pacific Rim countries including Australia, China, the Republic of Korea, Japan and the USA. Both are multi-authored reviews whose authors include a number of AVA board members. Agnes Tiwari, PhD, RN, Head of the School of Nursing at Hong Kong University and President-Elect of the AVA is charged with the review addressing the impacts of 
intimate partner violence upon youth. Un-Sun Chung, MD, $\mathrm{PhD}$ from Kyungpook National University Hospital in Daegu, Korea who serves as the Director of the School Mental Health Research and Resources Center funded by the National Ministry of Education is lead author of the review addressing rates of child maltreatment in Pacific Rim countries. Dr. Chung has worked diligently and passionately to advance the care for sexually abused and other traumatized children and parents in the Republic of Korea for more than a decade. She is one of the newest and youngest members of AVA's Board.

These reviews grew out of discussions between Dr. Chung and JKACAP Editor Geon Ho Bahn, MD. I thank both for the opportunity to invite these reviews from the AVA Board members and other colleagues. I have visited Seoul three times since 2010. Each time, I have been impressed by the kindness, diligence, and intelligence of the Korean professionals with whom I have been honored to meet. Seoul is an amazing city! The history of Korea is fascinating! Yours is an ancient, complex, and very productive culture. Sadly, during the last 120 years, Korea experienced the traumas of foreign occupation and war. The impacts of violence and abuse echo for generations. The USA still suffers in many ways from its history of slavery and the Civil War fought to end that abuse over 150 years ago. Those of us who are child psychiatrists and other health professionals can address the harms associated with violence and abuse. To do this, we need to learn as much as we can about the impacts of violence and abuse upon health, advocate for its prevention, early detection, and care for those who experience violence and abuse with compassion and effective treatment. In this shared mission, the KACAP and the AVA are now partners!

\section{REFERENCES}

1) Wiet S. Origins of addiction predictably embedded in childhood trauma: a neurobiological review. J Korean Acad Child Adolesc Psychiatry 2017;28:4-13.

2) Keeshin B, Strawn J. Pharmacologic considerations for youth with posttraumatic stress disorder. J Korean Acad Child Adolesc Psychiatry 2017;28:14-19.

3) Durrant JE, Ensom R. Twenty-five years of physical punishment research: what have we learned? J Korean Acad Child Adolesc Psychiatry 2017;28:20-24.

David L. Corwin, MD is a Professor and Director of Forensic Services in the Department of Pediatrics at the University of Utah School of Medicine in Salt Lake City. He currently serves as Board Chair for the Academy on Violence and Abuse and Vice-President of the American Professional Society on the Abuse of Children. He may be contacted at david.corwin@hsc. utah.edu. 